\title{
Fecal Calprotectin Levels Correlate With Main Domains of the Autism Diagnostic Interview-Revised (ADI-R) in a Sample of Individuals With Autism Spectrum Disorders From Slovakia
}

\author{
K. BABINSKÁ ${ }^{1}$, A. TOMOVA ${ }^{1}$, H. CELUŠÁKOVÁ ${ }^{1}$, J. BABKOVÁ ${ }^{1}$, G. REPISKÁ ${ }^{1}$, \\ A. KUBRANSKÁ ${ }^{1}$, D. FILČÍKOVÁ ${ }^{1}$, L. SIKLENKOVÁ ${ }^{1}$, D. OSTATNÍKOVÁ ${ }^{1}$ \\ ${ }^{1}$ Institute of Physiology, Academic Centre for Autism Research, Comenius University, Bratislava, \\ Slovak Republic
}

Received March 24, 2017

Accepted October 25, 2017

\begin{abstract}
Summary
Autism spectrum disorders (ASD) are neurodevelopmental disorders characterized by impaired social interaction and communication, as well as repetitive behavior and restricted interests. There is convincing evidence that the intestinal inflammation is involved in etiology of ASD. Increased levels of inflammatory markers were shown to be associated with more aberrant behaviors and communication of subjects with ASD. Calprotectin in the feces is produced by activated neutrophils and epithelial cells of the gut mucosa, and its levels reflect local inflammation of the gastrointestinal tract. Concentration of fecal calprotectin was determined by ELISA method in 87 individuals with ASD and 51 controls, of that 29 siblings of children with ASD and 22 non-related controls. In non-relatives significantly lower values of fecal calprotectin were observed than in both subjects with ASD and their siblings. In the group with ASD significant correlations of fecal calprotectin with all domains of the ADI-R diagnostic tool were found: qualitative abnormalities in reciprocal social interaction and communication, restrictive and repetitive patterns of behavior. Results suggest that low grade intestinal inflammation may be one of factors implicated in the pathophysiology of ASD.
\end{abstract}

\section{Key words}

Autism spectrum disorders • Fecal calprotectin • Siblings • ADI-R

- Behavior

\section{Corresponding author}

K. Babinská, Institute of Physiology, Comenius University Faculty of Medicine, Sasinkova 2, 81372 Bratislava, Slovak Republic. E-mail: katarina.babinska@fmed.uniba.sk

\section{Introduction}

Autism spectrum disorders (ASD) are neurodevelopmental disorders characterized by abnormalities in three domains: impaired social interaction, deficient verbal and non-verbal communication, and the presence of repetitive behavior and restricted interests (American Psychiatric Association 2013). It is a lifelong disability, which represents a serious public health concern due to its increasing prevalence rates (Christensen et al. 2016), severity of symptoms, and absence of a causal treatment (Volkmar et al. 2014).

Current understanding of the pathogenesis of ASD takes into account genetics along with the environmental factors, and various mechanisms have been suggested to be involved in abnormal development and function of the central nervous system in ASD, however neurobiological basis of the disorder remains poorly understood (Rossignol and Frye 2012). There is convincing evidence that the gut-brain axis, i.e. nervous and humoral signalling pathways from gut into the brain, is involved in the etiology of ASD. It has been shown that in the brain of individuals with ASD, there is an altered expression of genes associated with blood-brain-barrier integrity coupled with increased neuroinflammation and possibly impaired gut barrier integrity (Fiorentino et al. 2016). Except of the leaky gut, it may be other factors that are the cause of abnormal signalling from intestines to the brain. Major role is attributed to the abnormal composition of gut microbiota that was observed in individuals with $\mathrm{ASD}$, also intestinal inflammation and 
upregulation of proinflammatory cytokines in the gut mucosa of children with ASD has been reported (Van De Sande et al. 2014, Kushak et al. 2016) Moreover, increasing intestinal cytokine levels were associated with more impaired communication and aberrant behaviors (Ashwood et al. 2011).

Calprotectin is a cytoplasmic protein found mainly in neutrophils. Cell disruption and death trigger its release, however some is also actively secreted, and it has been detected in multiple types of body fluids. Presence of calprotectin in feces indicates neutrophil migration to and infiltration in the intestinal tract, and the level of fecal calprotectin (FC) correlates well with macroscopic and histological inflammation (Ikhtaire et al. 2016). FC has gained popularity because of its high sensitivity and specificity in the diagnosis of inflammatory bowel disease (IBD) in the adults, but also in children, and it is routinely used as a validated non-invasive marker of inflammation in IBD (Alibrahim et al. 2015). It is believed that FC is an under-appreciated marker with potential to serve as a diagnostic and follow-up tool for other gastrointestinal (GI) conditions. It has been studied as a potential marker of intestinal inflammation also in ASD (Fernell et al. 2007, De Magistris et al. 2010, Pusponegoro et al. 2015, Kushak et al. 2016).

The aim of present study was to assess the concentrations of fecal calprotectin in a sample of children with ASD and to investigate the correlations of this inflammatory marker with the core behavioral symptoms of ASD.

\section{Methods}

\section{Subjects}

The cross-sectional study involved 87 subjects (75 boys and 12 girls) with low functioning (classical) ASD aged 2-17 years (mean age 7.2 \pm 3.8 years). The control sample included 51 age-matched subjects with typical neurodevelopment (21 boys and 30 girls) aged 3-18 years (mean age $7.7 \pm 4.4$ years), of that 29 siblings of children with ASD and 22 non-related subjects. Individuals with associated genetic disorders, or history of recent inflammatory disease or digestive disorder were not included in the survey.

\section{ASD diagnostic tests}

The diagnosis of ASD was determined according to ICD-10 and DSM-V by trained examiners at the Academic Research Centre for Autism, Institute of
Physiology, Comenius University Faculty of Medicine. The diagnostic tools involved observation of a child by the Autism Diagnostic Observation Schedule - second edition (ADOS-2) (Lord et al. 2012), and the Autism Diagnostic Interview-Revised (ADI-R) (Lord et al. 1994). ADI-R was evaluated in areas of qualitative abnormalities in reciprocal social interaction and communication, as well as in restricted, repetitive and stereotyped patterns of behaviour. ADOS-2 was evaluated in domains of social affect, and restricted and repetitive behaviour scores. All children enrolled in the study had to meet criteria for ASD on both ASD diagnostic tools.

\section{Laboratory methods}

Stool specimens were collected by parents, kept at $4{ }^{\circ} \mathrm{C}$ and delivered to our laboratory at latest until the next day, where aliquots of $200 \mathrm{mg}$ of each specimen were frozen at $-80{ }^{\circ} \mathrm{C}$ until analysis. The method is based upon preparation of an extract of feces using the patented Fecal Extraction Buffer. Calprotectin was measured in stool samples using ALPROLAB ${ }^{\text {TM }}$ Calprotectin ELISA (ALP) (Calprolab, Lysaker, Norway) according to the instructions provided by the manufacturer. Fecal calprotectin levels below $50 \mu \mathrm{g} / \mathrm{g}$ of feces were regarded as are normal, $50 \mu \mathrm{g} / \mathrm{g}$ or more represented a positive test (Ikhtaire et al. 2016).

\section{Data analysis}

Software GraphPad Prism 7 was used for the data analysis. The statistical procedures involved the unpaired t-test (age), Mann-Whitney test, analysis of variance ANOVA, Chi-square test (FC). Spearman's correlation coefficient was calculated to test correlations between FC and behavioral markers. Values $\mathrm{p}<0.05$ were considered statistically significant. Levels of FC are presented as median and $95 \%$ confidence intervals.

The study protocol was approved by the Ethics Committee of the Comenius University Faculty of Medicine. Written informed consent was obtained from all the subjects or their caregivers. The study conformed to the code of ethics stated in the Declaration of Helsinki.

\section{Results}

The levels of FC were higher in subjects with ASD $(21.7 \mu \mathrm{g} / \mathrm{g} ; 95 \%$ CI $17.4-30.0 \mu \mathrm{g} / \mathrm{g})$ than in the control group including both siblings and non-relatives $(17.7 \mu \mathrm{g} / \mathrm{g} ; 95 \%$ CI $12.8-30.4 \mu \mathrm{g} / \mathrm{g})$, however, this difference was not statistically significant. When the 
control group was split into siblings of children with ASD and non-related individuals, significantly lower values of $\mathrm{FC}$ were found in non-related controls $(11.6 \mu \mathrm{g} / \mathrm{g} ; 95 \%$ CI $5.0-17.5 \mu \mathrm{g} / \mathrm{g})$ than in both subjects with ASD $(21.7 \mu \mathrm{g} / \mathrm{g} ; 95 \%$ CI $17.4-30.0 \mu \mathrm{g} / \mathrm{g})$ and also their siblings $(30.6 \mu \mathrm{g} / \mathrm{g} ; 95 \%$ CI $17.7-38.8 \mu \mathrm{g} / \mathrm{g})$, Figure 1. The median values of FC in subjects with ASD and their siblings were not significantly different.

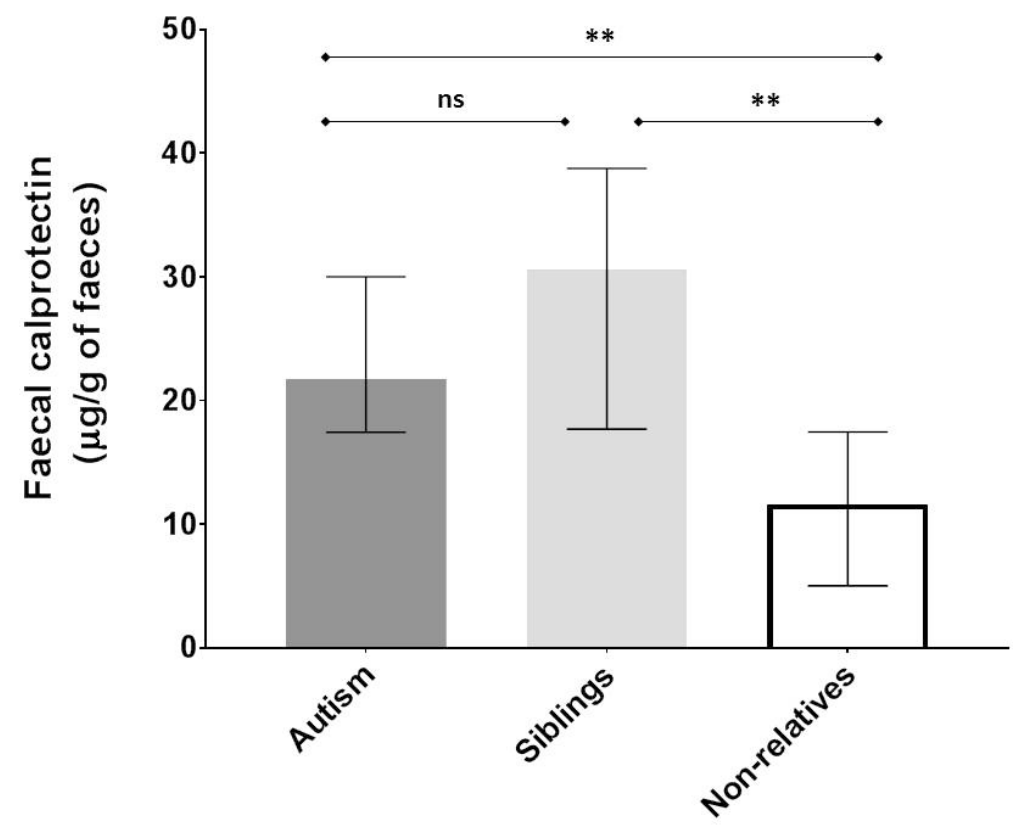

Fig. 1. Levels of fecal calprotectin in subjects with ASD, their siblings and non-related controls (median $\pm 95 \% \mathrm{CI}$ ), $* * \mathrm{p}<0.01$.

There was a trend towards higher prevalence of elevated levels of fecal calprotectin $(50 \mu \mathrm{g} / \mathrm{g}$ of feces or higher) in children with ASD (22.7\%) and their siblings $(20 \%)$ in contrast to the non-related controls $(9.1 \%)$, which, however was non-significant. No age or gender differences of the FC levels were found. Similarly, the FC levels of food supplement users, who were rather prevalent $(63 \%)$, and non-users were not significantly different.

In the group with ASD significant correlations of FC levels with all main domains of the ADI-R diagnostic tool were observed indicating that higher levels of $\mathrm{FC}$ are associated with more severe symptoms of ASD (Table 1). FC correlated with the ADI-R domain A: Qualitative abnormalities in reciprocal social interaction, $(\mathrm{r}=0.30$; $\mathrm{p}<0.01$ ), there was also a significant correlation between FC and ADI-R domain B: Qualitative abnormalities in communication $(\mathrm{r}=0.38 ; \mathrm{p}<0.001)$. Finally, FC levels significantly correlated also with ADI-R domain C: Restricted, repetitive, and stereotyped patterns of behavior $(\mathrm{r}=0.33$; $\mathrm{p}<0.01)$.

Table 1. Correlations between levels of fecal calprotectin and main domains of the diagnostic tool ADI-R.

Domains of the diagnostic tool ADI-R

A. Qualitative abnormalities in reciprocal social interaction

$0.30 * *$

B. Qualitative abnormalities in communication

$0.38 * * *$

C. Restrictive, repetitive and stereotyped patterns of behavior
$0.33 * *$

ADI-R - Autism Diagnostic Interview-Revised, $r$ - Spearman's correlation coefficient, $* * p<0.01 ; * * * p<0.001$.

\section{Discussion}

Elevated levels of inflammatory markers in individuals with ASD have been shown in several studies
(Xu et al. 2015, Rossignol and Frye 2012). Compared to serum markers, fecal markers are more specific and more successful in localizing inflammation in the intestinal mucosa. 
A few studies have addressed the levels of FC in ASD. In the study of De Magistris et al. (2010) pathological high mean value of FC was found in individuals with ASD indicating a mild degree of intestinal inflammation, while in our study the median concentration was in the normal range. In another survey, median levels of FC were also higher than in our study, but there were no significant differences between controls, children with mild and severe maladaptive ASD. Young age of the study individuals may be one of the contributory factors as children below 2 years have been reported with increased fecal calprotectin concentrations in the absence of any disease (Pusponegoro et al. 2015). Similarly, Kushak et al. (2016) reported no significant differences of FC between the groups of individuals with and without ASD. In earlier studies, that measured FC levels only in subjects with ASD without including control samples, only 2 out of 26 individuals with ASD had levels above the normal range (Wos et al. 2008), and 3 out of 21 subjects, respectively (Fernell et al. 2007).

The commonest level of FC for defining normality is $50 \mu \mathrm{g} / \mathrm{g}$ of feces. This level allows to detect individuals with inflammatory bowel disease with sufficient specificity and sensitivity, although for diagnostic precision the cut-off value of $100 \mu \mathrm{g} / \mathrm{g}$ is even better. Several other disorders have been shown to be associated with elevation of FC, and intestinal inflammation was a common feature of these conditions (Alibrahim et al. 2015). It is hypothesized, though, that different cut-off values of FC might be more adequate for patients with other conditions (Alibrahim et al. 2015, Montalto et al. 2013). This may apply also to ASD, since in association with this condition a chronic low grade inflammation has been reported (Skevaki et al. 2016).

A high prevalence of GI problems is reported in children with ASD (Van De Sande et al. 2014), and intestinal biopsy samples showed only mild levels of microscopic inflammation in some of the children with ASD who suffered also from gastrointestinal (GI) symptoms, but there seems to be no specific gastrointestinal pathology specific to ASD (Kushak et al. 2016). The most common gastrointestinal complaints resemble rather those of individuals with functional bowel diseases such as irritable bowel syndrome in which FC levels are lower in comparison to subjects with inflammatory bowel disease (Gijsbers et al. 2014). Raised fecal calprotectin should prompt further assessment in children with ASD and chronic intestinal symptoms, since organic bowel disorders, such as gastroesophageal reflux disease, or coeliac disease, are likely, which are reported to be more prevalent in ASD (Alibrahim et al. 2015).

In our samples only mild elevations of FC levels in the range of $50-100 \mu \mathrm{g} / \mathrm{g}$ were found, with exception of 1 child with ASD and 1 sibling whose levels exceeded $100 \mu \mathrm{g} / \mathrm{g}$. In the group with ASD even within this range of mostly normal and only in $22.7 \%$ of cases mildly elevated levels a correlation of FC with all domains of the diagnostic scale ADI-R was found, i.e. higher levels of FC were associated with more severe behavioral impairments whether in respect to qualitative abnormalities in reciprocal social interaction, or qualitative abnormalities in communication, and also in restricted, repetitive, and stereotyped patterns of behavior. This observation is in favor of the hypothesis that even mild forms of neutrophilic infiltration and/or intestinal inflammation may influence the brain functions.

Interestingly, in our study not only the concentrations of FC of children with ASD, but also of their siblings were significantly higher than the levels in the control group. Also, in our previous survey, tumor necrosis factor alpha ( TNF $\alpha$ ) was assessed and a trend of elevated levels of this inflammatory marker were observed not only in the group of children with autism, but also in their siblings compared to the control group (Tomova et al. 2015). Significantly higher FC have been also found in $49 \%$ of first-degree relatives of patients with Crohn's disease, also in first-degree relatives of patients with colitis ulcerosa as compared with controls. On the other hand, significantly higher FC levels were found also in a group of spouses than in controls and lower in respect to relatives. This suggests that both genetic and environmental factor may be responsible for changes of the markers od intestinal inflammation (Montalto et al. 2013).

Limitation of our study is the small sample size, especially when the control group was split into subgroup of siblings and non-relatives, as well as overrepresentation of girls in the control sample, even though no gender differences of FC were found. Also, no verification of possible symptoms of ASD was done in the control group beyond the parental report. Additional factors that might have been a cause of elevated FC levels, such as nutritional or gastrointestinal factors were not analysed.

In conclusion, the median concentrations of FC observed in subjects with ASD, but also in their siblings were significantly higher than in controls. There 
was only low prevalence of elevated concentrations of FC in subjects with ASD, predominantly in the range of only mild elevation. Even within the range of mostly normal and mildly elevated levels, the higher concentrations of FC were associated with more severe behavioral impairments. The results support the hypothesis that low grade intestinal inflammation can be one of factors involved in pathomechanisms of ASD. Further research is needed to bring more light into this topic and to establish if FC is a valid biomarker in ASD.

\section{Conflict of Interest}

There is no conflict of interest.

\section{Acknowledgements}

Supported by grants APVV-15-0085, APVV-15-0045, APVV 0254-11.

\section{References}

ALIBRAHIM B, MOHAMMED IA, BALJINDER S: Fecal calprotectin use in inflammatory bowel disease and beyond: a mini-review. Can J Gastroenterol Hepatol 29: 157-163, 2015.

AMERICAN PSYCHIATRIC ASSOCIATION: Diagnostic and Statistical Manual of Mental Disorders: DSM-5. American Psychiatric Association, Washington, D.C. 2013, 947 p.

ASHWOOD P, KRAKOWIAK P, HERTZ-PICCIOTTO I, HANSEN R, PESSAH I, VAN DE WATER J: Elevated plasma cytokines in autism spectrum disorders provide evidence of immune dysfunction and are associated with impaired behavioral outcome. Brain Behav Immun 25: 40-45, 2011.

CHRISTENSEN DL, BAIO J, VAN NAARDEN BRAUN K, BILDER D, CHARLES J, CONSTANTINO JN, DANIELS J, DURKIN MS, FITZGERALD RT, KURZIUS-SPENCER M, ET AL.: Prevalence and characteristics of autism spectrum disorder among children aged 8 years--Autism and Developmental Disabilities Monitoring Network, 11 Sites, United States, 2012. MMWR Surveill Summ 65: 1-23, 2016.

DE MAGISTRIS L, FAMILIARI V, PASCOTTO A, SAPONE A, FROLLI A, IARDINO P, CARTENI M, DE ROSA M, FRANCAVILLA R, RIEGLER G, ET AL.: Alterations of the intestinal barrier in patients with autism spectrum disorders and in their first-degree relatives. J Pediatr Gastroenterol Nutr 51: 418-424, 2010.

FERNELL E, FAGERBERG UL, HELLSTRÖM PM: No evidence for a clear link between active intestinal inflammation and autism based on analyses of faecal calprotectin and rectal nitric oxide. Acta Paediatr 96: 1076-1079, 2007.

FIORENTINO M, SAPONE A, SENGER S, CAMHI SS, KADZIELSKI SM, BUIE TM, KELLY DL, CASCELLA N, FASANO A: Blood-brain barrier and intestinal epithelial barrier alterations in autism spectrum disorders. Mol Autism 7: 49, 2016.

GIJSBERS CF, BENNINGA MA, SCHWEIZER JJ, KNEEPKENS CM, VERGOUWE Y, BÜLLER HA: Validation of the Rome III criteria and alarm symptoms for recurrent abdominal pain in children. J Ped Gastroenterol Nutr 58: 779-785, 2014.

IKHTAIRE S, SHAJIB MS, REINISCH W, KHAN WI: Fecal calprotectin: its scope and utility in the management of inflammatory bowel disease. J Gastroenterol 51: 434-446, 2016.

KUSHAK RI, BUIE TM, MURRAY KF, NEWBURG DS, CHEN C, NESTORIDI E, WINTER HS: Evaluation of intestinal function in children with autism and gastrointestinal symptoms. J Pediatr Gastroenterol Nutr 62: 687-691, 2016.

LORD C, RUTTER M, LE COUTEUR A: Autism diagnostic interview-revised: a revised version of a diagnostic interview for caregivers of individuals with possible pervasive developmental disorders. J Autism Dev Disord 24: 659-685, 1994.

LORD C, RUTTER M, DILAVORE PC, RISI S, GOTHAM K, BISHOP S: Autism Diagnostic Observation Schedule, Second Edition. Western Psychological Services, Torrance, CA, 2012.

MONTALTO M, GALlO A, SANTORO L, D’ONOFRIO F, LANDOLFI R, GASBARRINI A: Role of fecal calprotectin in gastrointestinal disorders. Eur Rev Med Pharmacol Sci 17: 1569-1582, 2013. 
PUSPONEGORO HD, ISMAEL S, SASTROASMORO S, FIRMANSYAH A, VANDENPLAS V: Maladaptive behavior and gastrointestinal disorders in children with autism spectrum disorder. Pediatr Gastroenterol Hepatol Nutr 18: 230-237, 2015.

ROSSIGNOL DA, FRYE RE: A review of research trends in physiological abnormalities in autism spectrum disorders: immune dysregulation, inflammation, oxidative stress, mitochondrial dysfunction and environmental toxicant exposures. Molec Psych 17: 389-401, 2012.

SKEVAKI C, VAN DEN BERG J, JONES N, GARSSEN J, VUILLERMIN P, LEVIN M, LANDAY A, RENZ H, CALDER PC, THORNTON CA: Immune biomarkers in the spectrum of childhood noncommunicable diseases. J Allergy Clin Immunol 137: 1302-1316, 2016.

TOMOVA A, HUSAROVA V, LAKATOSOVA S, BAKOS J, VLKOVA B, BABINSKA K, OSTATNIKOVA D: Gastrointestinal microbiota in children with autism in Slovakia. Phys Behav 138: 179-187, 2015.

VAN DE SANDE MM, VAN BUUL VJ, BROUNS FJ: Autism and nutrition: the role of the gut-brain axis. Nutr Res Rev 27: 199-214, 2014.

VOLKMAR F, SIEGEL M, WOODBURY-SMITH M, KING B, MCCRACKEN J, STATE M: Practice parameter for the assessment and treatment of children and adolescents with autism spectrum disorder. J Am Acad Child Adolesc Psychiatry 53: 237-257, 2014.

WOS H, KOMRAUS M, KAZEK B, MARSZAŁ E, GRZYBOWSKA-CHLEBOWCZYK U, WIECEK S: Faecal calprotectin in children with autistic spectrum disorders. Arch Dis Child 93: 215, 2008.

XU N, LI X, ZHONG Y: Inflammatory cytokines: potential biomarkers of immunologic dysfunction in autism spectrum disorders. Med Inflamm 2015: 1-10, 2015. 